\title{
ADEQUAÇÃO DOS CUSTOS DA ATIVIDADE AGRÍCOLA
}

\author{
Otília Denise Jesus Ribeiro ${ }^{1}$
}

\section{RESUMO}

O trabalho "Adequação dos Custos da Atividade Agrícola" trata de um estudo dos tipos de atividades agrícolas - cultura temporária e cultura permanente. Após o entendimento e da correta classificação dos tipos de culturas é possível classificar os tipos de custos existentes nas duas culturas. Haja vista a importância de se manter um sistema de custos que reflita a realidade da empresa, é imprescindível a escolha de um método de apuração de custos que possa atender as necessidades de controle e decisão dentro de uma empresa agrícola. Para o bom entendimento de como se efetuar a correta apuração de custos através desses sistemas, se faz necessário a verificação de alguns conceitos dentro da área de custos. É importante desenvolver um bom sistema de controle interno dentro das empresas agrícolas, pois, dentro das particularidades dessas empresa, destaca-se o desenvolvimento a céu aberto em grandes extensões de terras, e o empreendedor não poderá controlar tudo o que se passa na empresa, no desenvolvimento da atividade. Para concretizar e mostrar o estudo teórico foi desenvolvido um exemplo hipotético de controle e apuração dos custos em um empresa que possua cultura temporária. E para finalizar é concluído com a importância de se manter um bom sistema de custos que reflita a realidade, para que possa dar condições ao empreendedor de competir em uma economia globalizada.

\footnotetext{
${ }^{1}$ Contadora e Professora do Centro Universitário Franciscano - UNIFRA - Santa Maria - RS denisejr@terra.com.br
} 


\section{INTRODUÇÃO}

Voltado para um gerenciamento mais dinâmico diante das exigências de um mercado cada vez mais competitivo, torna-se imprescindível que as empresas, independente do seu porte, utilizem meios de apuração de custos de seus produtos, tendo em vista que a apropriação da parcela dos diversos custos que compõem o produto final é tarefa difícil e complexa e de grande necessidade para os usuários.

As atividades agrícolas são exercidas das mais variadas formas, desde o cultivo caseiro para a própria subsistência até os grandes complexos, na grande maioria das vezes não utilizam adequadamente os meios sendo de vital importância para a economia mundial.

Apesar disso e do avanço das tecnologias modernas, observa-se que o papel do controle de custos e administração como responsáveis pelo controle econômico das atividades e seus eventos, não têm desempenhado a mesma razão, deixando muitas vezes os administradores dos empreendimentos agrícolas sem ferramentas necessárias para a tomada de decisões seguras.

Uma das principais ferramentas que $o$ administrador possui é procurar por todos os meios, reduzir os seus custos de produção, os quais são representados pelos custos de utilização dos insumos, mão-de-obra e máquinas.

A apuração do custo da produção em uma empresa agrícola segue alguns dos processos utilizados em uma empresa industrial qualquer, observando algumas particularidades inerentes ao tipo de atividade.

Dentre essas particularidades aparecem: o crescimento natural da produção, que deverá ser de alguma forma avaliado e considerado na apuração dos custos; se desenvolve a céu aberto, muitas vezes em grandes extensões de terra, co distanciamento dos trabalhadores e dos administradores durante a jornada de trabalho; em vista de se desenvolver a céu aberto está vulnerável a mudanças climáticas; não é contínua durante o ano variando em função da estação, que propicia o tipo de cultura a ser desenvolvida; predomina o trabalho manual sobre o mecanizado, exceto em grandes culturas onde o aparelhamento mecânico e a utilização de máquinas resulta em economia; apresenta dificuldades quanto a controles mecânicos e 
automático do rendimento de cada tarefa desempenhada. a relação custo/benefício de se manter controles mais complexos em busca de informações mais precisa deve ser sempre considerada por outro lado a necessidade de controles, por mais simples que pareçam ser, torna-se fator imprescindível quando se tratar de valorização dos estoques agrícolas.

Neste sentido o presente estudo visa desenvolver em estudo racional das particularidades dos custos componentes do processo de produção agrícola com a utilização adequada dos métodos de custeamento., fornecendo ao empreendedor agrícola das pequenas e médias empresas e aos estudiosos da matéria, subsídios necessários e simplificados de apropriação adequada dos custos na produção agrícola: culturas temporárias e culturas permanentes. .

\section{DESENVOLVIMENTO}

De acordo com MARION (1996, p. 43), "agricultura é definida como a arte de cultivar a terra. Arte essa decorrente da ação do homem sobre o processo produtivo à procura da satisfação de suas necessidades básicas"

A atividade agrícola é classificada em dois tipos de culturas existentes: culturas temporárias e culturas permanentes.

\subsection{Culturas Temporárias}

Segundo CREPALDI (1993, p.56) "são consideradas culturas temporárias aquelas sujeitas ao replantio após a colheita com um período de vida curto, normalmente não superior a um ano ". Após a colheita são arrancadas do solo para que seja realizado um novo plantio. São também chamadas como cultura anual. Exemplo: soja, milho, arroz, entre outras.

Dessa forma as plantações com prazo inferior a um ano, passam a ser temporárias, mesmo que com mais de uma produção ou colheita nesse prazo.

Também são consideradas temporárias aquelas que tenham vida inferior a três anos, normalmente no máximo de 2 anos, desde que produzam uma única colheita. 
A cultura temporária é formada por diversos custos, entre eles, sementes, inseticidas, adubos, mão-de-obra, gastos indiretos de produção, entre outros.

\subsection{Culturas Permanentes}

Segundo CREPALDI (1993, p. 56), "são consideradas culturas permanentes as que não estão sujeitas ao replantio após a colheita, com um período de vida longo, normalmente em torno de três a quatro anos". Exemplo: citricultura (laranja, limão), café, entre outras.

CREPALDI (1993) ainda ressalta que deverão serem encaradas como culturas permanentes aquelas que permanecem vinculadas ao solo, têm um prazo de maturação e produção superior a, pelo menos um ano, produzem mais de uma vez em sua vida útil econômica, ou mesmo as que produzem uma única vez, mas têm prazo de maturação e produção acima do razoável, normalmente acima de dois anos.

Nessas culturas, os custos são acumulados no "Ativo Permanente" numa conta provisória de "Cultura Permanente em Formação". Dentro desta conta há sub-contas que indicam, especificamente, o tipo de cultura.

Tanto a cultura temporária com a cultura permanente, para um melhor controle a apuração dos custos poderão ser subdivididas por operações.

Segundo MARION (1996) essas operações são classificadas como: preparo do solo/calagem, plantio/adubação, adubação, tratamento fitossanitário, cultivo manual, cultivo mecânico, cultivo químico, raleação, irrigação, manutenção, poda, colheita e outras.

O conhecimento do custo da produção agrícola classificada distintamente nos dois tipos de cultura, e ainda por operações dentro dessas culturas é importante principalmente devido a controle e decisão do empreendedor agrícola.

Para que os custos sejam perfeitamente atribuíveis a produção se faz necessário um estudo dos custos e a identificação destes com a mesma. Para isso é importante que a pessoa responsável pelo departamento de produção conheça conceitos básicos utilizado na contabilidade de custos.

A apuração dos custos em uma empresa é a contabilidade de custos, que no entender de LOPES DE SÁ (1993, p. 93), "é a parte da contabilidade 
que estuda os fenômenos dos custos, ou seja, dos investimentos feitos para que se consiga produzir ou adquirir um bem de venda ou um serviço."

\subsection{Custos}

Para LOPES DE SÁ (1993, p. 109), "custos é o investimento para que se consiga um bem de uso ou de venda".

No entender de MARION (1994), custo rural agrícola é o relativo às atividades das lavouras, que compreende todos os gastos feitos desde a preparação da terra até o ponto da colheita.

A classificação dos custos depende de fatores tais como identificação com a produção ou relação com o volume dessa produção e classificam-se em:

4.3.1 Custos Diretos: MARION (1996, p. 61), "são os identificados com precisão no produto acabado, através de um sistema e um método de medição, e cujo valor é relevante, como horas de mão-de-obra, quilos de sementes ou rações; gastos com funcionamento e manutenção de tratores".

4.3.2 Custos Indiretos: MARION (1996, p. 61), "são aqueles necessários à produção, geralmente de mais de um produto, mas alocáveis arbitrariamente, através de um sistema de rateio, estimativas e outros meios. Exemplo salários dos técnicos e das chefias, materiais e produtos de alimentação, higiene e limpeza (pessoal e instalações ).

4.3.3 Custo Fixo: MARION (1996, p. 61), são aqueles que permanecem inalterados em termos físicos e de valor, independente do volume de produção e dentro de um intervalo de tempo relevante. Geralmente são oriundos da posse de ativos e de capacidade ou estado de prontidão para produzir. Exemplo depreciação de instalações, benfeitorias e máquinas agrícolas, seguro de bens, salários de técnicos rurais e chefias".

4.3.4 Custo variável: MARION (1996, p. 61), "são aqueles que variam em proporção direta com o volume de produção ou área de plantio. Exemplo mãode-obra direta, materiais diretos ( fertilizantes, sementes, rações ), horas máquinas."

\subsection{Custeio}


LOPES DE SÁ (1993, p. 108), trata custeio como o "ato de apropriar despesas, controlar custos ou registrar gastos feitos para manter alguma coisa".

Devido ao custo do produto ser composto de vários elementos e nem todos estes serem diretamente imputáveis ao produto, como vistos acima é que existem os sistemas de custeio.

Baseado em matéria publicada na IOB - (Informações Objetivas) (1996), utiliza-se os sistemas de custeio com a finalidade de atribuir custos aos diversos bens ou serviços produzidos pela empresa. Esta atribuição se faz pela computação direta ou por alocação, sendo aquela quando o custo é identificável diretamente ao produto e esta quando os gastos não são atribuíveis de forma direta ao produto, devendo seguir critérios de rateio.

Os rateios são técnicas usadas para distribuir os custos que não conseguem ser vistos com objetividade e segurança a quais produtos se referem. Tais técnicas envolvem um elevado componente de risco, devido ao grau de arbitramento, sendo que qualquer imprecisão, por menor que seja, na seleção do critério utilizado pode causar desvios significativos no resultado final obtido. A melhor técnica de rateio para determinado custo é aquela em que o custo indireto guarde estreita correlação com os dados escolhidos como base de rateio. A escolha das bases deve ser considerada em função dos fatores mais relevantes do produto.

MARTINS (1993) apresenta algumas maneiras de se efetuar o rateio dos custos indiretos em uma empresa:

a) rateio com base em horas máquina - onde a base é o número de horas em que as máquinas são utilizadas na produção.

b) rateio com base na matéria-prima aplicada - onde a base é a matéria-prima aplicada na produção, que guarda estreita relação com a produção.

c) rateio com base na mão-de-obra - onde a base é a mão-de-obra utilizada na produção.

d) rateio com base nas unidades produzidas - onde a base é as unidades produzidas.

Atualmente existem vários sistemas de custeamento usados com vantagens e desvantagens, os quais não devem ser confundidos com os 
métodos de avaliação de estoques que englobam exclusivamente, procedimentos necessários ao registro da movimentação dos estoques.

4.4.1 Custeio direto - LOPES DE SÁ (1993, p. 108) "define custeio direto como sendo o processo de apuração de custo que exclui os custos fixos", apenas os custos variáveis serão atribuídos aos produtos elaborados. Alguns autores também o chamam de custeio variável em razão da exclusão dos custos fixos.

4.4.2 Custeio por absorção - LOPES DE SÁ (1993, p.109), trata o custeio por absorção como sendo "o processo de apuração de custos que se baseia em 'dividir' ou 'ratear' todos os elementos do custo de modo que cada 'centro' ou 'núcleo' absorva ou receba aquilo que lhe cabe por 'cálculo' ou 'atribuição'”.

O custo de produção inclui os gastos com administração de produção, departamento de programação e controle, almoxarifado de matérias-primas e demais materiais, além do pessoal aplicado na produção, as depreciações dos equipamentos e outras amortizações de investimentos.

CREPALDI ( 1998 p. 203 ) trata o custeio por absorção como " a apropriação de TODOS os custos ( sejam eles fixos ou variáveis) à produção agropecuária do período. Os gastos não produtivos ( despesas ) são excluídos. A distinção principal no custeio por absorção é entre custos e despesas. A separação é importante porque as despesas são jogadas imediatamente contra o resultado do período, enquanto somente os custos relativos aos produtos vendidos terão idêntico tratamento". O mesmo autor relata os seguintes passos que devem ser seguidos no custeio por absorção:

a) separação dos gastos o período em custos e despesas;

b) classificação dos custos em diretos e indiretos;

c) apropriação dos custos diretos aos produtos agropecuários;

d) apropriação, através de rateio, dos custos indiretos de produção.

\subsubsection{Sistema de custeio por atividade (ABC) - Segundo MARTINS} (1993 p. 112), o sistema $A B C$ "é uma ferramenta que permite melhor visualização dos custos através da análise das atividades executadas dentro da empresa e suas respectivas relações com os produtos". O mesmo autor afirma que para se utilizar o sistema $A B C$, é necessária a definição das 
atividades relevantes dentro dos departamentos, bem como dos direcionadores de recursos que irão alocar os diversos custos incorridos às atividades..

\subsection{Controle Interno de uma empresa agrícola.}

Controle interno segundo ATTIE (1983) compreende os organogramas e fluxuogramas e todos os métodos, procedimentos e medidas coordenados e princípios, adotados em uma empresa, para:

a) salvaguardar os seus ativos;

b) possibilitar uma administração condigna de suas operações;

c) assegurar o correto registro de suas transações;

d) promover maior eficiência operacional;

e) divulgar os resultados econômicos;

f) prevenir ou facilitar a revelação de enganos.

Numa empresa agrícola é fundamental um bom sistema de controle interno que permita ao administrador o acompanhamento do desenvolvimento de cada etapa do desenvolvimento da cultura, bem como a verificação das alocações dos diversos insumos que compõem essas culturas.

Segundo RIBEIRO \& BULEGON (1997) é possível criar os controles dos diversos custos utilizados na produção, através de planilhas de simplificadas que são descritas abaixo:

4.5.1Controle dos insumos utilizados - Para controlar os insumos utilizados, na produção, será preenchida uma requisição de materiais onde conste o tipo de produção (cultura) e a operação que utilizará o insumo, seguido da quantidade, unidade, e especificação do tipo de insumo.

Essa requisição será preenchida pela pessoa que utilizará o insumo, sendo revisada pelo encarregado do controle da produção que entregará a mesma ao responsável pelo almoxarifado, que dará a respectiva baixa do estoque.

Feita a entrega do material ao encarregado, a requisição será remetida ao departamento que efetua o registro e controle dos custos das produções.

A seguir estão dispostas sugestões de planilhas para coleta e controle de insumos utilizados na produção. 
Planilha para controle de insumos diretos

\begin{tabular}{|l|c|c|}
\hline \multicolumn{2}{|c|}{ REQUISIÇÃO DE MATERIAIS DIVERSOS } & №: \\
\hline PRODUÇÃO & OPERAÇÃO & DATA \\
\hline & & \\
\hline
\end{tabular}


Planilha para controle dos gastos indiretos

\begin{tabular}{|l|c|c|}
\hline \multicolumn{2}{|c|}{ CONTROLE DE GASTOS INDIRETOS } & No: \\
\hline ELEMENTO & DATA & \\
\hline & & \\
& & \\
& & \\
Responsável: & & \\
Revisado: & TOTAL (R\$) \\
\hline
\end{tabular}

Fonte: RIBEIRO \& BULEGON - Trabalho de Graduação - UFSM - 1997.

4.5.2 Controle da mão-de-obra utilizada - Para um controle da mão-de-obra utilizada na agricultura, o responsável pelas produções deverá manter um registro por tipo de cultura das horas utilizadas para a realização dos trabalhos necessários em uma determinada operação, onde conste o nome do funcionário e o horário de início e término do trabalho. Para o cálculo do custo de mão-de-obra deverá ser levado em conta todos os encargos incidentes sobra cada funcionário ( fiscais e sociais).

Esse registro será preenchido pelo funcionário que efetuar o serviço, e será revisado pelo encarregado da produção entregará a mesma ao departamento de controle de custos.

A seguir está disposta uma sugestão de planilha para coleta e controle de horas trabalhadas na produção. 
Planilha para controle da mão-de-obra

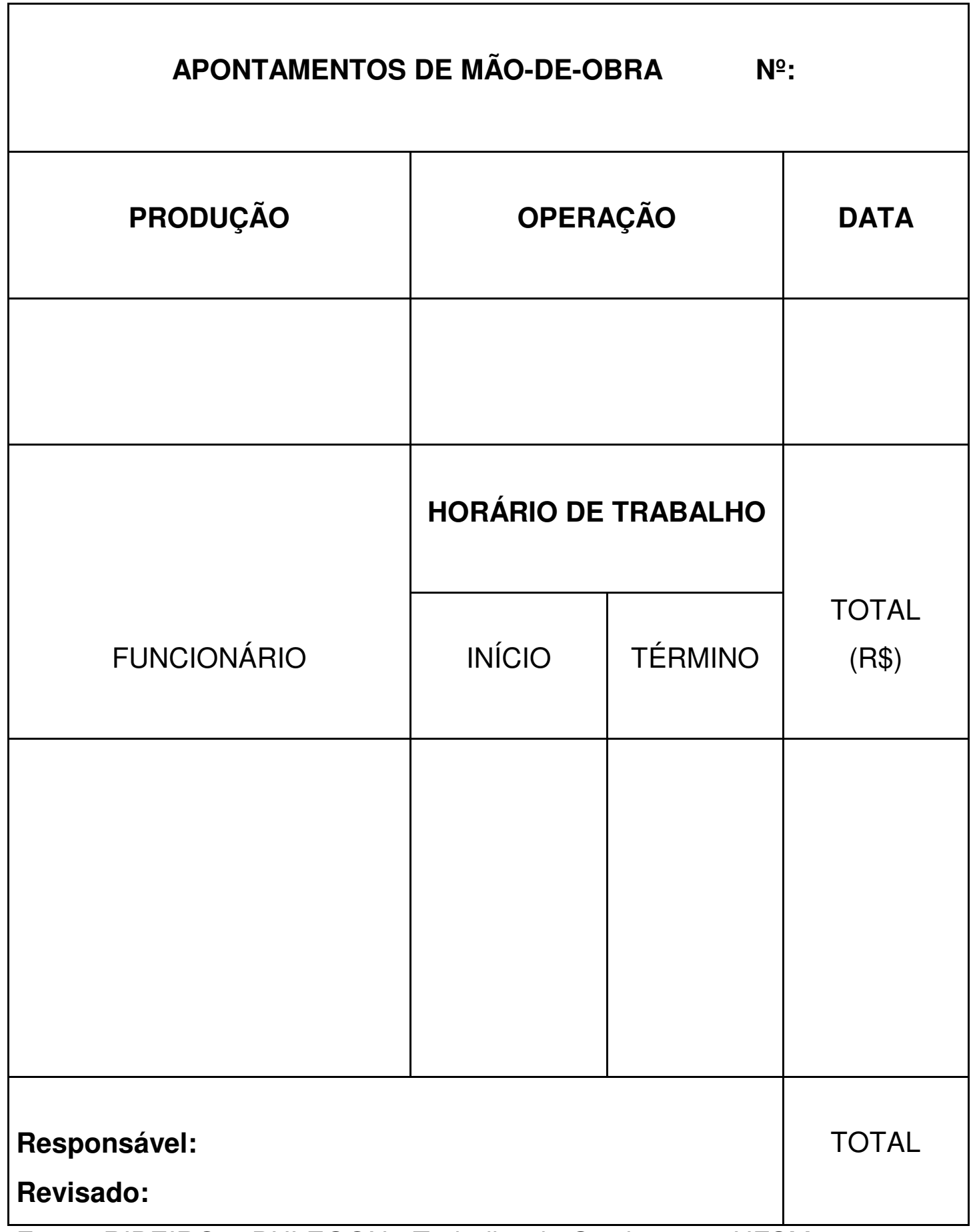

Fonte: RIBEIRO \& BULEGON - Trabalho de Graduação - UFSM - 1997.

4.5.3Controle das horas máquinas trabalhadas para cálculo da depreciação

O cálculo da depreciação das máquinas e implementos agrícolas será efetuado com base em horas trabalhadas. 
O controle dessas horas será realizado mediante o preenchimento de uma ficha que deverá conter o nome do equipamento, o tipo de produção, a operação e ainda a hora inicial e final que o bem permaneceu em uso.

Essa ficha será preenchida pela pessoa que utilizará o equipamento, sendo revisada pelo encarregado da produção.

Após a revisão, essa ficha será entregue ao departamento de registro e controle dos custos, que efetuará o lançamento.

Segue abaixo a sugestão de uma planilha para coleta e controle de horas trabalhadas na produção.

Planilha para controle de horas máquina para cálculo da depreciação

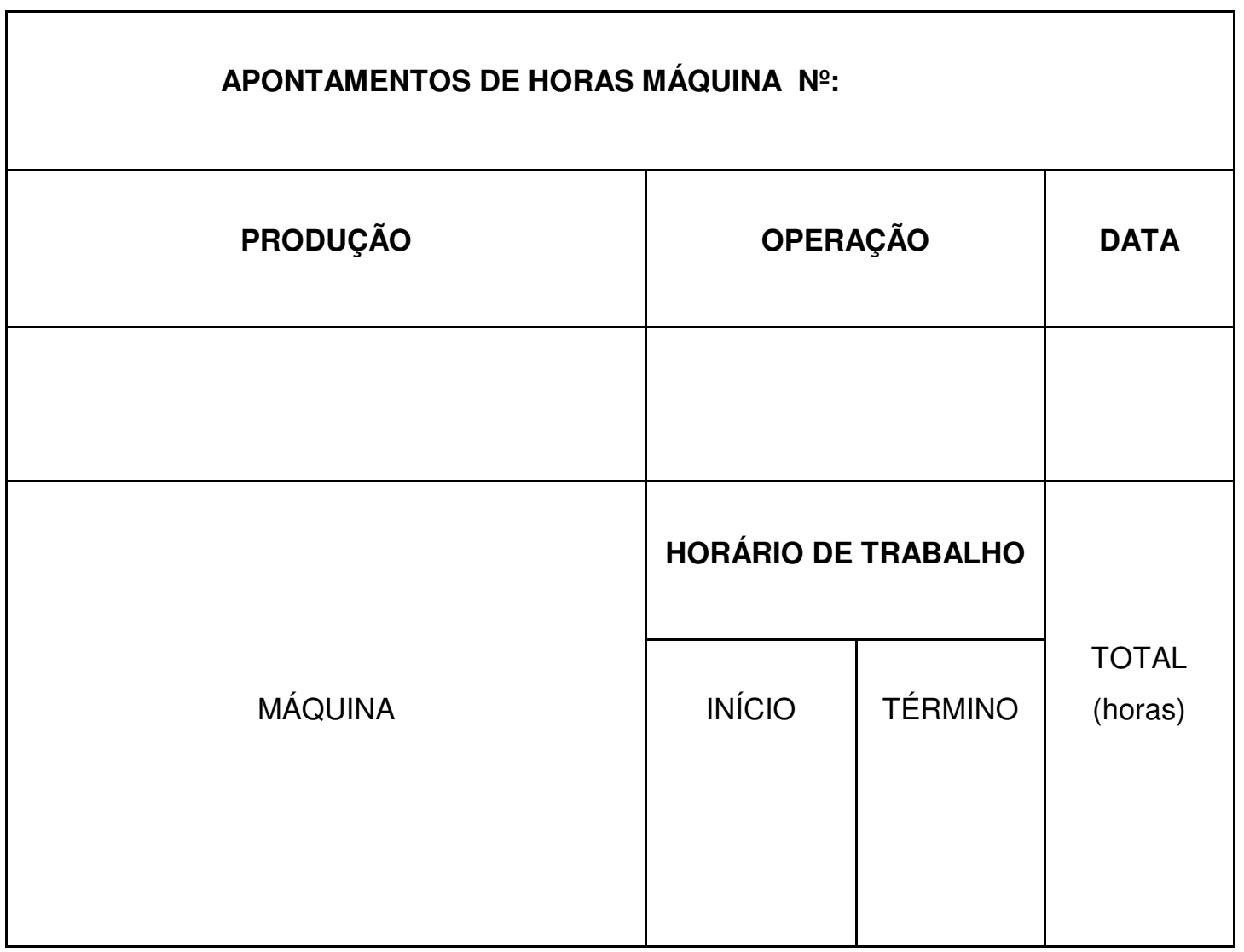

Fonte: RIBEIRO \& BULEGON - Trabalho de Graduação - UFSM - 1997.

4.6 Aplicação Prática em uma empresa agrícola que explora atividade agrícola temporária e utiliza o método de custeamento por absorção.

Consideremos uma empresa que explore exclusivamente atividade agrícola cultura temporária, em um determinado período da sua atividade. As 
despesas do período já foram separadas dos custos de produção e já foram levadas a resultado do exercício.

\begin{tabular}{|l|r|}
\hline \multicolumn{1}{|c|}{ CUSTOS } & \multicolumn{1}{c|}{ R\$ } \\
\hline Sementes & $3.500,00$ \\
\hline Inseticidas & $2.300,00$ \\
\hline Adubos & $3.600,00$ \\
\hline Combustíveis & $2.800,00$ \\
\hline Engenheiro Agrônomo & $2.100,00$ \\
\hline Mão-de-obra Plantação & $1.800,00$ \\
\hline Mão-de-obra Manutenção & $1.300,00$ \\
\hline Mão-de-obra Supervisor & $1.200,00$ \\
\hline Depreciação trator & 350,00 \\
\hline Depreciação Caminhão & 350,00 \\
\hline Mão-de-obra Colheita & $1.900,00$ \\
\hline Energia Elétrica & $2.900,00$ \\
\hline & $24.100,00$ \\
\hline
\end{tabular}

A separação e classificação dos custos foram baseados na coleta de dados através da utilização das requisições de materiais e as anotações de mão-de-obra juntamente com os respectivos encargos.

A seguir será demonstrado os cálculos dos custos das culturas:

\begin{tabular}{|l|r|r|r|r|}
\hline \multicolumn{1}{|c|}{ Custos } & $\mathrm{R} \$$ & Cultura Arroz & Cultura Milho & \\
\hline & & & & \\
\hline Sementes & & Custos Diretos & $\begin{array}{r}\text { Custos } \\
\text { Diretos }\end{array}$ & $\begin{array}{c}\text { Custos } \\
\text { Indiretos }\end{array}$ \\
\hline Inseticidas & $3.500,00$ & $2.100,00$ & $1.400,00$ & \\
\hline Adubos & $2.300,00$ & & & $2.300,00$ \\
\hline Combustíveis & $3.600,00$ & & & \\
\hline Eng. Agrônomo & $2.800,00$ & & & \\
\hline Mão-de-obra Plan. & $2.100,00$ & & & \\
\hline Mão-de-obra Manut. & $1.300,00$ & & $2.300,00$ & \\
\hline
\end{tabular}


Revista Gletrônica de Gontabilidade

Gurso de Giências Gontábeis UFFSH

VOLUME I. N.1 SET-NOV/2004

\begin{tabular}{|c|c|c|c|c|}
\hline Mão-de-obra Supervisor & $1.200,00$ & & & $1.200,00$ \\
\hline Depreciação Trator & 350,00 & & & 350,00 \\
\hline Depreciação Caminhão & 350,00 & & & 350,00 \\
\hline Mão-de-obra Colheita & $1.900,00$ & $1.250,00$ & 650,00 & \\
\hline Energia Elétrica & $2.900,00$ & & & $2.900,00$ \\
\hline & $24.100,00$ & $7.640,00$ & $4.460,00$ & $12.000,00$ \\
\hline Cultura Arroz & $\mathbf{R} \$$ & $\mathbf{R} \$$ & $\%$ & \\
\hline & Custos Diretos & Custos Indiretos & Custo Total & \\
\hline Operação Plantio & $5.500,00$ & $5.453,78$ & $10.953,78$ & \\
\hline Operação Manutenção & 890,00 & 882,70 & $1.772,70$ & \\
\hline Operação Colheita & $1.250,00$ & $1.240,32$ & $2.490,32$ & \\
\hline & $7.640,00$ & $7.576,80$ & $15.216,80$ & \\
\hline & Custos Indiretos & & & \\
\hline Cultura Arroz 63,14\% Cl & $7.576,80$ & & & \\
\hline & $\%$ & & & \\
\hline Operação Plantio & 71,98 & & & \\
\hline Operação Manutenção & 11,65 & & & \\
\hline Operação Colheita & 16,37 & & & \\
\hline & 100,00 & & & \\
\hline Cultura Milho & $\mathbf{R} \$$ & $\mathbf{R} \$$ & $\%$ & \\
\hline & Custos Diretos & Custos Indiretos & Custo Total & \\
\hline Operação Plantio & $3.400,00$ & $3.183,82$ & $6.583,82$ & \\
\hline Operação Manutenção & 410,00 & 515,30 & 925,30 & \\
\hline Operação Colheita & 650,00 & 724,08 & $1.374,08$ & \\
\hline & $4.460,00$ & $4.423,20$ & $8.883,20$ & \\
\hline & Custos Indiretos & & & \\
\hline Cultura Milho 36,86\% Cl & $4.423,20$ & & & \\
\hline & $\%$ & & & \\
\hline
\end{tabular}




\begin{tabular}{|l|r|l|l|l|}
\hline Operação Plantio & 76,23 & & & \\
\hline Operação Manutenção & 9,20 & & & \\
\hline Operação Colheita & 14,57 & & & \\
\hline & 100,00 & & & \\
\hline & & & & \\
\hline Custo Total da Produção & $24.100,00$ & & & \\
\hline
\end{tabular}

Suponhamos que a empresa rural vendesse sua produção à vista no mercado interno, o Arroz por $R \$ 25.000,00$ e o Milho por $R \$ 20.000,00$, o resultado apurado com base na apropriação dos custos, seria o seguinte:

Cultura Arroz

Venda de produção - 25.000,00

Custo da produção - $15.216,80$

Resultado

\section{Cultura de Milho}

Venda da produção - 20.000,00

Custo da produção - $8.883,20$

Resultado

Portanto, fica evidenciado nesse exemplo hipotético, que o empreendedor agrícola obteve uma margem maior na cultura de milho, e que o insumo contribuiu em grande parte, para alcançar esse resultado.

Se a empresa não utilizasse o sistema de custeamento, o resultado seria semelhante e o empreendedor não poderia precisar qual a cultura mais rentável nessa safra.

Finalmente, o estudo comparativo realizado nos permite afirmar que, para o processo de produção agrícola é indispensável a utilização adequada dos métodos de custeamento que seja perfeitamente identificado com a atividade rural e de fácil aplicação. E ainda, que os custos apurados em qualquer sistema sejam registrados na contabilidade, para adequada apuração do valor tributável, e principalmente para fins gerenciais dos interessados. 


\section{CONCLUSÃO}

É sabido que o custo de produção do setor agrícola é influenciado por vários fatores tais como o clima, tipo de cultura, genética desenvolvida e principalmente encargos pagos decorrentes do financiamento obtido junto ao Sistema Nacional de Crédito Rural. Com a mudança da política econômica, a partir da década de oitenta, o Estado foi obrigado a disponibilizar aos agentes financeiros uma quantia de recursos cada vez menor para o plantio e comercialização dos produtos agropecuários com a cobrança de taxas de juros semelhantes às existentes no mercado. Essas medidas, levará o setor agrícola brasileiro, adoção de uma tecnologia moderna, especialização da mão-de-obra, redução e racionalização dos custos de produção agrícola.

A propósito do custo de produção, tema desenvolvido no presente trabalho, foi demonstrado que as empresas agrícolas poderão utilizar as formas desenvolvidas para redução e controle dos custos sem ferir os princípios e critérios técnicos.

Com essa proposta desenvolvida no trabalho será possível aos acionista ou quotistas acompanhar o crescimento e manutenção do capital empregado nas empresas agrícolas, bem como proporcionar o atendimento do mercado, cada vez mais exigente em qualidades de produção com preços menores e competitivos.

\section{BIBLIOGRAFIA}

ATTIE, William. Auditoria conceitos e aplicações. São Paulo: Atlas, 1983.

CREPALDI, Silvio Aparecido. Contabilidade rural uma abordagem decisorial. São Paulo: Atlas, 1993.

Silvio Aparecido. Contabilidade rural uma abordagem decisorial. 2. ed. São Paulo: Atlas, 1993.

INFORMAÇÕES OBJETIVAS. IOB - Temática contábil. № 10. março, 1996.

MARION, José Carlos. Contabilidade rural. 3. ed. São Paulo: Atlas, 1994. José Carlos. Contabilidade e controladoria em agribusiness. São Paulo: Atlas, 1996. 
MARTINS, Eliseu. Contabilidade de custos. 4. ed. São Paulo: Atlas, 1993.

SÁ, A. Lopes de, SÁ, A. M. Lopes de. Dicionário de contabilidade. 8. ed. São Paulo: Atlas, 1993.

RIBEIRO, Otília Denise Jesus \& BULEGON, Jociane. Contabilidade de custos integrada com a contabilidade rural, Santa Maria - 1997 ( Trabalho de Graduação - UFSM ) . 